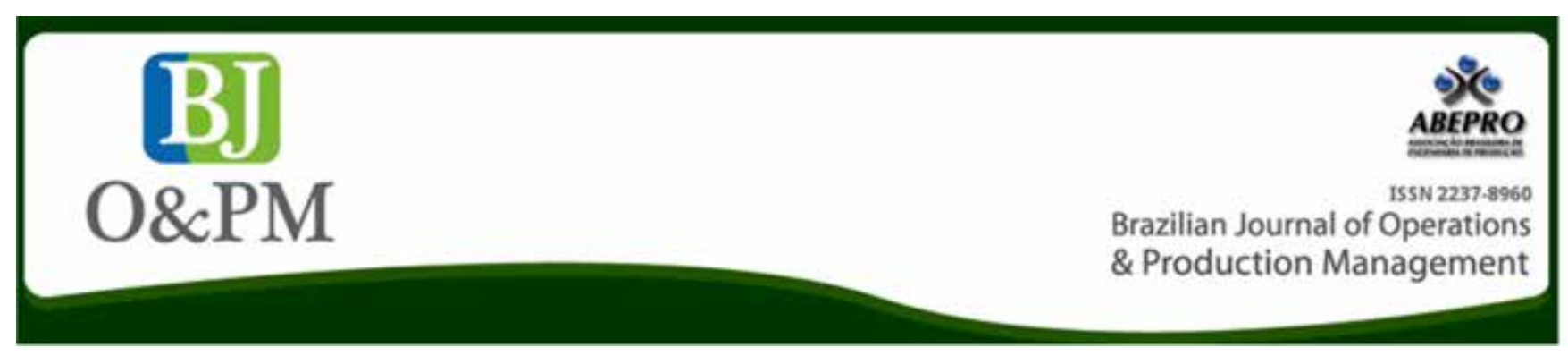

\title{
WORKERS, PRODUCERS AND THE CREATIVE EXPERIENCE
}

\section{Alice Itani}

aliceitani@gmail.com

São Paulo State University - UNESP

São Paulo, São Paulo, Brazil.

\section{Fernando Rei}

fernandorei@ig.com.br Catholic University of Santos UNISANTOS, Santos, São Paulo, Brazil.

\begin{abstract}
Creative activities assume a measure of importance within what is known as the creative economy. Little is known, however, about the challenges and prospects that present themselves to those who work in those activities that are considered to be creative. The objective of this paper is to analyze workers' experiences, especially in individual projects. Statements were taken from workers who have already worked in companies. The experiences of these workers were analyzed on the basis of what they express in relation to the items: their relationship with the activity, the product, or the result of the work; their relationship with the time and value of the work; their understanding of creation; their possibility for creating; their mastery of the work process; and their understanding of the work process. It was found that the women in the cases chosen are highly trained for developing their particular activity and have a relationship with it that is highly positive. They recognize that their activity is of value to society. The value of the work, however, is related to the time spent on the activity, which has not been remunerated for a long time. There are challenges for those who depend on the time taken to sell the product, a process that is carried out with little support. Everyone masters and understands the work process undertaken in the activity, and they identify the product, or the result of their work. They realize that there are many possibilities for creation. Even when an idea has been developed before, there is the possibility of innovating.
\end{abstract}

Keywords: creative economy; creative experience; creative activities; work experience in creative activities; producers. 


\section{INTRODUCTION}

\section{What experiences do workers have in creative activity?}

The term creative economy emerged in the 1990s and brought to the fore the producers and distributors of goods and services. What is different about the activities of the creative economy is the fact that they are knowledge-based (Florida, 2002; Howkins, 2001), mainly as far as concerns research, technology, education and culture. Other terms are also simultaneously linked as the terms creative culture and creative sectors. Many of these activities are related to the arts, as in the case of popular culture, handicrafts and painting, as well as the visual arts, theater, cinema, music, literature, design, architecture and fashion. There are also activities supported notably by information and communication technologies, as is the case with software programs, games, video games, and TV and radio programs. There is an association between technology and innovation; however, technology alone does not leverage the economy. With regard to this particular point, Florida (2002) considers that this sector mobilizes what he called the 3T: talent, technology and tolerance; he considered tolerance since various social groups are present in these activities, which is why he thought it to be a sector that is open to a degree of equal opportunity. An open country (Florida, 2006) enables their development, which is evident because of the emergence of entrepreneurs, artists and professionals seeking new ways of developing their activities. He considers the creative classes to be those professionals who use their creativity and the symbolism to create new ideas, new technologies or new creative content in the areas of science, engineering, architecture, design, education, the arts, music and entertainment (Florida, 2006). Miguez (2007) believes that the creative economy involves services that are based on texts, symbols and images and he refers to the distinct set of activities, with their differential based on creativity, talent or individual ability, whose products incorporate intellectual property and include everything from traditional handicrafts to the complex production chains of culture industries.

In the case of Brazil, the government's Creative Economy Department launched a plan in 2011 with the objective of transforming culture into a development instrument. This plan included policies, guidelines and actions for the creative economy sector in the period between 2011 and 2014. In 2012, the Creative Economy Department was set up as part of the Ministry of Culture with the mission of formulating, implementing and monitoring public policies for local and regional development, prioritizing support for and the fostering of professionals and micro and small creative Brazilian enterprises. Creative sectors were defined as being those whose production activities have as their main inputs creativity and knowledge, and which are characterized by their infinite variety and abundance, and not by scarcity (Brasil, 2012).

In fact, the activities included in these sectors of the creative economy produce income, employment and wealth. According to data from Oliveira et al. (2013) and according to the PNAD [National Household Sampling Survey] data, which represents some 583,000 jobs registered on the RAIS [Social Information Annual List] in 2010, some 4 million workers are formally or informally involved in these sectors in Brazil. According to the Unctad report (2010), the export of creative goods and services has been growing by $14 \%$ a year since 2002. A panorama of the creative economy in the country was carried out by Oliveira et al. (2013), who mainly analyzed companies that were considered to be creative. The creative economy in Brazil contains both potential and challenges, according to the analysis of Kon (2016), based on the Fundap and Firjan reports.

Creative activities seem to be concentrated in large cities. In fact, cultural activities, such as the plastic arts in galleries or museums, the performing arts in show venues, concert halls, dance salons, theaters, architectural works and fashion shows are largely present in the major centers. In the case of Brazil, it is common for handicraft products, lace, decorative objects, ornaments and pots to be sold in the major centers where there is a greater flow of people.

There is, therefore, a great variety of diverse activities in these creative sectors that have different configurations. The spectrum of activities considered in these creative sectors ranges from individual, family, community, creative city and regional projects to what is called creative industries, economic groups, such as those that were analyzed by Oliveira et al (2013), which include advertising agencies, telecommunications and the media in general. Little is known, however, about worker experiences in these creative activities. The perspective of this text is to analyze the individual experiences of workers in these creative activities.

\section{ACTIVITIES IN THE CREATIVE SECTORS IN LOCAL AND REGIONAL PROJECTS}

The Brazilian experience in terms of creative activities is rich, because of the country's cultural diversity, marked notably by informality. Aside from the creative industry, which is composed of companies, there are individual projects and collective projects in which people as individuals, groups, communities, cities and even regions are involved. These experiences are to be found in various regions in the country. Nicolaci-da-Costa (2016) analyzes the cases of young talented people in the country who developed on the basis of their individual creation, but also in a group, based mainly on internet resources, both for developing projects and publicizing 
Brazilian Journal of Operations \& Production Management

Volume 15, Número 3, 2018, pp. 386-395

DOI: 10.14488/BJOPM.2018.v15.n3.a5 events, whether they are musical happenings, games or any other creation they produced.

There are collective projects that can be identified and disseminated in the social fabric, while there are also projects located in small and medium-sized communities and based particularly on traditional knowledge. The case of the lace-makers in the countryside region of states such as Rio Grande do Norte, Ceará and Pernambuco is exemplary. Lace-makers' work usually relies on the whole of the family being involved in producing lace. Maria José lives in a community in Pernambuco and says she learned to work with lace when she was young. Even today she makes it the "way I learned". She has worked for more than 40 years and she has developed new patterns and a new way to earn more money. "Before, I made dresses and it took some six months. Now, I only make skirts and blouses. Even so, it takes three months to make a lace blouse." She and other lace-makers used to offer their products for sale at fairs and in stores. They became known because their photos were divulged as part of tourism. Now there are many merchants and market-traders who order her items and come and fetch them from her. Maria José says that "storekeepers increased her sales and they sell her products at a higher price, but these lace-makers receive much less. If we ask for another price, they complain and they don't want pay." The remuneration of the lace-makers has improved; however, Maria Jose's daughters do not want to carry on making lace. They want to work in the city in order to have a better life. The lace-makers in some communities have organized themselves to sell their own production. As a result, many of the communities produce orders for stores in other states and even for other countries and this has improved the living conditions of lace-makers.

Similarly, small communities in the interior of Minas Gerais produce clay pots following traditional knowledge. Many families devote their time to producing pots following the knowledge passed on to them by older people. Tião is one of these craftspeople who produce clay pots by hand, just as his father did. Tião works from age six. He developed new techniques to improve the pots, "because the food made in this pan is not the same". He shows the clay to prepare the pots and states the following: "this concavity... it needs to store heat. It's important to keep the heat". He complains, however, that many pans are now being made by machine and in any fashion, and that they are being sold in stores. Many of these small communities also have groups of craftspeople producing sculptures and paintings. It can be identified theater groups with forms of theatrical expression produced by them. Although many of these activities have a low profile, they have the potential for holding the region together.

There are also whole communities dedicated to a particular collective creative project. The term creative com- munities can be attributed to them, as in the case of the community named Bichinho. This community emerged in a small neighborhood called Vitoriano Veloso, located between Prados and Tiradentes in Minas Gerais. Craftspeople develop products, notably adornments, ornaments and objects made from clay, wood, metal and other recyclable materials. This traditional gold mining region received a boost in the 1990s when the August Workshop was set up on the initiative of a local artist, a location that is currently used by most of the local craftspeople. Each craftsperson develops their own proposal from an idea and discusses it in the workshop where they can develop better techniques and improve their use of colors and materials. The production of the Bichinho craftspeople is currently well known in Brazil and abroad and can be found in many stores in major cities. The locality has also become a tourist attraction, located on the border between Tiradentes and São João Del Rey. Not all the craftspeople, however, can earn enough to support their families. Such is the case with João, who works from ten to twelve hours a day. To produce an item, he has to spend time designing it, searching for materials, outlining, and working on it. This takes between 40 and 60 days. When he manages to produce an object, there is still the time it takes before he is able to sell it. When an item is made to order, it is easier, since he already has a defined customer. But, the items he puts up for sale in houses and stores are not always sold immediately. Storekeepers also set their own prices and haggle with João, who does not always get the value of the time he spent on it.

There are also creative regions, such as the Jequitinhonha Valley, where production activities can be found involving both embroidery and handicrafts based on clay and wood that depict local figures. Similar examples can also be found in communities in the Amazon region, where producers develop activities creating adornments, costume jewelry and useful objects using discarded wood from the region. These are regions in which traditionally small-scale production is found that developed with the increase in techniques and other incentives for regional production.

There are also creative regions that emerge from the symbolism of the images of Guimarães Rosa, such as the case with Arinos and the Chapada Gaúcha, which was researched by Meyer et al (2016). The symbolism of Guimarães Rosa, from literature to image worship and divulging source places, distinguishes the region as being a literary landscape, of having an immaterial value that has encouraged tourism and increased local craftsmanship in the backlands of Minas Gerais.

There are also localities that organize popular traditional festivals. Such is the case, for example, of Cirio de Nazaré, which is a festival that mobilizes the surrounding communities. Each of these festivities features a large number of cre- 
ative embroidery activities, the production of masks, ornaments and a variety of clothing items, as well as painting and the setting up of tableaux. The celebration with its traditional procession, which first appeared in Belém do Pará as a religious feast, paying homage to Our Lady of Nazareth, also became a celebration with a variety of symbols. Currently, other communities in the region also organize the same festivity.

Creative activities have always been present in many traditional communities. In small communities, restricted visibility did not always make it possible for many of the manifestations, as some of the popular expressions became known. Even so, many resisted and were transformed into immaterial cultural heritage that has no material value, but that is of economic value in terms of regional development. Incentives and public policies aimed at handicrafts and regional tourism in Brazil made it possible for many of these communities to become visible because of their activities.

It should be stressed, however, that many of these creative regions, despite their precariousness, remain attentive to public policies. Some of these regions are developed with the support of associations and the development of local production arrangements. These activities can serve, therefore, as a source of income and employment for the local population; communities depend on an initial visualization and appreciation of their local and regional, traditional art. They depend on public policies for developing as immaterial heritage and bearing fruit in terms of economic value.

\section{THE EXPERIENCE OF WORKERS IN CREATIVE ACTIVITIES}

Does experience show that the producers and creators of culture are valued by the creative economy? The question might seem deliberately provocative. What is the relationship of these workers with this activity? The interest in analyzing worker experiences is focused on the perspective of determining whether there is a prospect of creation, if there is mastery of the process and how this appreciation is perceived by a producer. An attempt has been made here to analyze the experience of workers with the creative activities that were considered within these creative sectors.

This item presents the experiences of workers who undertake activities within individual projects. Their experience was analyzed with the aim of identifying those projects in which this particular project distinguishes itself from all the others, as well as identifying the challenges they face and their prospects. Statements were taken following ethical standards and only the first name was given in order to protect the individuals interviewed. Some passages were transcribed, according to the statement given. This experience was interpreted on the basis of the perspective of Gianini
(2013), understood as being the way in which the worker explains and understands the work process. This comes from what the worker, whose words are not passive, states, from his identity situation as a symbol of human singularity, about the result of knowledge and of created references with their own meanings, and that is expressed by way of statements. This experience is analyzed using six items (Itani, 2014): mastery of the work process and its comprehention; understanding the types of creation; relationship with the activity; relationship with the work product; relationship with time; and the value of the work. From those interviewed, four cases were selected: Maria, Cleu, Julia and Maria Nita.

Maria is an actress since 1979. She trained long and hard for this and had a focus on theater for the last 40 years, included a formation in a university. She took courses in games and theatrical interpretation with the best acting masters, went to corporal drama and movement school and attended the Jacques Lecoq International Theater School. She also has a degree in theater studies. She did internships in professional training, actor training courses and contemporary dance and singing courses. She had the chance to work in big theaters and at that time she was well paid. When she set out to participate in theater groups, which was much more interesting to her, she found that it was poorly paid work. In order to survive, she started becoming involved with other activities, as a theater teacher and a journalist. Since 2004, she has dedicated herself to play readings and interpreting texts of non-theatrical, novels, poetry, essays.

She believes that the product of her work in the theater is the interpretation of a character also the author's word. She directed her interpretation to the general public when she was playing in large theaters. She currently depends on places for her presentations and theatrical projects. There is the possibility of greater interaction in small theaters, or in communities.

She notes that there is a lot of ambiguity in the theater. When the theater is supported and prices are lower, there is not always a large audience. However, Maria comments, audiences do not worry about paying a much higher price when the actors are on television, even when the play is mediocre.

Maria considers that her work has an important value, difficult in seeing economic results, but it makes places of entertainment. In the live show it is a lived experience with the audience in the time of the representations and this experience of the representation produces reflection and emotions, since the theater has an indispensable function in society. The fact of being a live spectacle increases the release of emotions and catharsis. It helps examine a theme or a reality and allows for important reflection. A theatrical performance can remain as a profound memory in the theater-goer, sometimes for years. 
Brazilian Journal of Operations \& Production Management

Volume 15, Número 3, 2018, pp. 386-395

DOI: 10.14488/BJOPM.2018.v15.n3.a5
With regard to creation, Maria believes the theater is always a collective art. Whether a solo performance, or with various actors, there is always a team involved: the actors, the author of the text, the production research team, the director, the set designer, the lighting and sound technicians, those who look after costumes, communication and publicity and assisting the audience. However, this involves a lot of individual work on the part of actors, who devote many hours a day, over and above rehearsal times, so that the role is well interpreted. Maria considers that what is interesting in theatrical work is that a presentation evolves. Once the play has been staged, it can undergo modifications according to audience receptivity. It can also undergo adaptations, according to where the play is being staged.

She notes that, when she dedicates herself to play readings, which involves interpretation, singing and dancing, this evolution is much greater. In this case the audience is smaller and there is a closer relationship with the theater-goers. Audience receptivity contributes to this evolution and even the presentation itself evolves.

With regard to the time she dedicates to her work, Maria considers that some plays need a lot of time to stage. In these cases, it is necessary to have the means for maintaining oneself and the team during that time. Pay is always a delicate matter. She works much more than the working time she is paid for. The hours of rehearsal, extra rehearsal time at home, try-outs for learning the text, the moves, the time researching and reflecting on the characters or creation aspects are not counted. This time offers no return. This does not include the time needed for preparing the project, presenting the projects, auditions, the publicity presentation and other aspects.

The theatrical activity is a source of creation, of discovery, and of joy; however, it obliges those involved to alternate between intense work and the absence of work. It is a sector that is in both constant and intermittent flux. This is very much harder for women. Women of a certain age are less likely to get a role. There is always a preference for young actors, even if they have no experience. She would like the theater to be more supportive and offer support so that actors would have a remuneration that would allow them to maintain a minimum subsistence level. She would also like the theater to have professionals who could help support actors with regard to the search for resources and to take care of publicity, both of which occupy a lot of an actor's time. Working in theater groups should also be more privileged, and the time involved with preparing and presenting projects should also be remunerated. Culture everywhere has been receiving less attention. She stresses that if there were more artists in society, there would be fewer sick people in it.
Maria Nita was trained as a teacher. She did an internship and worked for many years as a teacher in four institutions of higher education, in a variety of undergraduate and specialization courses. However, the teaching profession has fallen sharply, both as far as its value is concerned in society, as well as with regard to remuneration and respect within educational institutions. She is currently dedicating herself to writing. Her experience is related to an activity that requires a table and hours sitting in a chair. When she was a teacher, she wrote because she needed to plan the material she taught and structure the content well, in accordance with her responsibilities as a teacher. She has found that working as a writer she can have the prospect of transmitting culture and knowledge to a larger group of people and making a contribution to society. She realized that this was what most enabled her to feel the result. Seeing a written text with a beginning, middle and end is the result of a process involving technique, research, organization, and dedication. Producing a book involves planning, outlining the idea and researching. This production is aimed at a reader and she always thinks about what can make a difference to the people who will read the book. She sees the value of her work as being twofold: that of developing a narrative, an argumentative text, or a short story, and what can make a contribution to culture.

With regard to the time she devotes to this activity, she is disciplined and dedicates herself to it at least four hours a day. Some days she manages to write for more than ten hours. On other days, she is unable to write for more than five hours. She is aware that writing is not an activity that can be done whenever a person wants. Some experienced writers, after many years of writing, are able to devote many hours a day to it. She is not always able to write everyday either. To start writing writers need to outline what they are going to write, draw up a plan, and do some research. Every detail needs to be checked in order to have the correct information. She outlines the bare bones of the work from an idea and researches the elements that will be part of the text. Knowledge is important for determining the authenticity of the text, above all when it comes to chronology and the spatiality of places. The character she creates needs to be coherent with the reader's world, with a narrator being used or not. The reader needs to identify with some of the details in order to keep on reading. She says she has mastered the writing process, based on what she intends to write about however, she does not always have this mastery during the whole of the writing process. The process is sometimes spread out, especially when she needs to stop to take care of other things she has to do. There are times when words "hide themselves", so she goes out for a walk, or she goes to the movies.

What is different in this work process is that it is precisely the process that counts. Maria Nita believes it is necessary 
to rely on experience, because that serves as the basis, as elements of yeast and rich ingredients for her writing. Writing is a work of creation using these ingredients, seeking better ways of conveying an idea and, at the same time, enabling the reader to journey with you through time and places. The writing technique helps make these elements stand out and the narrative to have a dialogue with culture.

What started out as an obligation and a necessity has become a rewarding activity. Over time she has gradually developed the writing skill and has mastered the art. She is aware that few writers survive on a writer's pay. She must have initial support in order to dedicate herself. Great writers manage to live on their writing; they sell a lot. Others devote more time than the return they expect to get. Writing time is a time that cannot always be measured, but she knows that her bills need to be paid. Thus, writing time is shared with the time needed to take care of her survival.

Cleu studied occupational therapy and then psychology. She worked in a government agency. After graduating, she opened a clinic and spent two years dividing her time between working as a civil servant and the clinic. She found, however, that the clinic was not giving the financial return she had predicted it would. At the same time, she felt trapped in a job in public administration that made no sense. She began to think of other ways that could give her a return in terms of income and, at the same time, combine the possibility of having both an income and pleasure. She decided to learn how to sew. She started to accumulate three activities: a civil servant during the day, the psychology clinic owner at night and sewing in the early morning hours and on weekends. She could not stand the pace. Exhaustion struck and she stopped going to the clinic. Leaving her employment was not yet an option. As soon as she began her sewing activity, it became clear that creation, color, and form provided her with a lot more pleasure. The new activity grew until finally, in 2012, after six years working in the state government, she was able to resign and dedicate herself fully to her own activity. She created her own brand and set up a website. She has more 10 years in her production.

When she is producing, she does not initially visualize what might be salable, since she prioritizes the creation process. For her, this process of creation is developed much more as an expression of what she considers esthetically interesting. She knows, however, who her biggest public is; most are women between the ages of 24 and 45, and mainly resident in Rio de Janeiro and São Paulo.

She considers that her work has a lot of worth, because she uses traditional handicraft techniques and is concerned with valuing Brazilian culture, particularly popular culture. In the production process she is also careful with regard to the durability of the items she makes, she uses Brazilian raw materials and pays attention to the disposal of the waste she produces in the process.

What is very interesting in the case of Cleu is that she has mastered the entire work process and knows that the product is the result of her creation. Cleu believes that this creation, as any other, develops from her own cultural baggage, the knowledge she has in terms of how to master the techniques and materials available in the market. This is why her creation has always been moving ahead, right from the beginning. As part of her proposed intention to interpret artistic and cultural references and transform them into products that have an identity of their own, she has been improving.

She dedicates herself fulltime to this work and works on her own in creation and production. She relies on her partner for some of the more bureaucratic matters, such as issuing invoices and studying publicity. She feels that she spends a lot of time dedicating herself to necessary activities. She does not feel professional in areas that are necessary, such as publicizing the products, photographing them, divulging them on the social networks, creating graphic material, and looking for business opportunities, sales and service. What she would really like is to devote more time to creating and developing products.

Regarding the financial return, she does not believe that it is compatible with the time dedicated to the activity. This is because she spends a lot of time dealing with publicity and sales activities. But if she had the option she would hire a professional to look after the administrative activities and publicity and then she could dedicate herself more to creation.

The results of her work today are handmade textile creations, cushions, blankets, prons, bags, and accessories for personal use. They are characterized as having their own identity and durability. There is a concern in this process with prioritizing traditional techniques, above all specifically crochet and embroidery. This is mainly because of the possibility of being able to involve other women in the production process. Today the crochet work, for example, is not done by Cleu, but by a partner craftswoman.

This current activity differs from her previous two jobs. She stresses two points that are fundamental in this current work: first, the possibility of creation, and second, the materiality of this work because of its results. For example, when she was working in the clinic, she always missed these two points. When she attended someone in the clinic she missed the type of work where she could clearly see the result, with a beginning, middle and end. In her opinion, attending a patient was putting herself at the service of the patient, in their time, and the "results" are subjective, subtle, and usually long-term. Since she prioritized assisting children, she was also subject to another variable: the wishes of the parents. 
Brazilian Journal of Operations \& Production Management

Volume 15, Número 3, 2018, pp. 386-395

DOI: 10.14488/BJOPM.2018.v15.n3.a5
When she produces an item, this process is very different, since "inspiration defines the techniques, performances, and evaluations". There is a process in mastery, and "creativity coagulates into an object that is concrete and palpable." Yet, she thinks that there is a possibility for creation in the psychology clinic; however, it is different because that type of creation is the result of working closely with the patient. As to her work in public administration, on the other hand, there are no doubts. She missed these two points a lot. That really was "dry, repetitive work, with no room to make any kind of contribution."

Julia has a degree in digital media. She enrolled on a digital technology course when it was one of the first being offered in this area. She was from the first class. When she was in her third year of college, she joined a consultancy company as an intern. She started her internship in a small business, a startup. Because it was a small company, she had to perform various roles at the same time. Soon, the company began to grow and the number of clients increased, and she started "sorting herself out" and being a "Jill of all trades": designer, project manager, programmer, illustrator, etc. At the same time, "there were many opportunities for proactive creativity." As she had to create screens that conversed with the user, she found it easier to "create something visual that communicated a message than having to depend on other people." After four years and already working as a freelancer in the same consulting company, she decided to pursue her studies. She did a Master's degree in computer technology and then was engaged on a consulting project for colleges that develop e-learning material, as a result of which she developed various projects for a variety of higher education institutions. She currently works in a consultancy firm whose clients are government research agencies. She also works on her own, developing individual projects.

For Julia, the product of her work is "learning experiences, whether that is an image, a digital history, a course, a video, or a digital product aimed at teaching", which transmits an idea, a message, a fact or a value. That is why, when she prepares her work she always visualizes the person who is going to experience this learning, which is usually an economically productive adult; they are professionals.

She understands that this product is aimed at learning, since "learning doesn't only happen when a person looks at a screen." She passes on understanding when she prepares a digital experience, because it is possible to provoke the user, to make the user reflect, to look at things in a different way, to perform a task in a different way or to carry out a completely new task. This provocation experience is an initial element, but "this has a cumulative effect, like a snowball." Learning can begin on the screen; however, the user will continue the learning process by other means, by either interacting with people, with the environment, or with other products.
This is why she is aware that her work is of value to society; always. After all, is this not the value of work?

The work she does is an individual process, but she believes that it is also a collective process. This is because, in a creative process, it can never be said that someone has complete mastery of creation. The process is always evolving, and it evolves with you and with other people. The idea and the development of the creation process may be considered hers. However, she considers that, with approximately 200,000 years of humanity, it is quite possible that what she thinks she is creating now has already been created or thought about at other times. Likewise, with regard to the creative process, when she starts from an idea, this might be the re-creation of something that has already been constructed. Obvioulsly, there are more chances of improving something that has already been proved to work. In any event, she believes it is also always possible to innovate in this improvement process.

With regard to time, she would definitely like to have more of it; always more time. Working constantly without a break does not allow her brain to rest and process thoughts, to have the chance for new ideas to flourish, or to be able to think about new approaches. Experience has shown her that a break always leads to gains in terms of creation. When a new project begins she normally starts with something simple, an idea that suddenly emerges. She then takes a break and does something else. When she returns to the project, she can see other aspects that begin to appear from what she initially created.

With regard to remuneration she thinks that, sometimes, what she receives is compatible with the time she spends. When she develops a project she always focuses on the end user. She tries to understand what people are like and what they need. Thus, this is the perspective she works with. Based on the images she has in her mind, she does not keep imagining any human being who would do something similar to what she does. With regard to what she would change in her work, she would like to be more courageous, less fearful.

\section{CREATION AND THE EXPERIENCE}

Does the experience with creative activities differ from other experiences? Workers in the salary relationship within the capitalist industrial society have always been the subject of studies and this can be seen from the extensive literature on the subject. With regard to workers who are outside this salary relationship and engaged in various types of activities, such as those who are self-employed, those who do odd-jobs on a casual basis, or even those who provide services for families and, in general, cannot be regarded as salary-earners. They are, however, still subject to the same production mode regime, as Boyer (1998) analyzed. 
Transforming what is established, however, creating, innovating, modifying and improving are human skills. Creation is part of the human condition. The creative men or women give form to matter as part of their human condition in society as it institutes itself and is instituted, and transform what is given, as is defined within the theoretical perspective of Castoriadis (1982; 1987). Creation, therefore, is part of the experience of the worker as producer; however, this is rarely considered in studies on the capitalist mode of production. There are no studies that highlight creation as part of the work process, and neither are there methodological categories that make such studies possible. There is no denying, however, that there is innovation or even creation in many work processes; even those involving tasks that are fragmented and standardized. The academic challenge is to look for what can be considered within these fragments, since not everything can be considered as being established within a mode of production, and what seems to be determined, is not always actually so.

Those activities included as being part of the sectors that are considered creative are not, in fact, new; not even those activities that are considered to be part of cultural economics, and that are found in what is termed the "culture industry", within the perspective of Adorno et Horkheimer (1985), as a system, a mass culture. What is new in these activities is their use of information and communication technologies for producing, circulating or distributing products. The term "creative economy" appears in the 1990s as a public policy proposal from the perspective of taking advantage of sectors that until then were not at the center of the economy, thereby seeking to leverage the potential of these sectors.

What is considered part of the creative activities or creative sectors is the value attributed to this creation. In several regions in the country, it is also possible to identify what can be termed "creative energy" with innovation and knowledge that is present in the local social fabric.

The relevance of the producers and distributors who are involved with these categories of creative activity is not found in the type of product, since the products and services are the result of a work process that is not specific to these sectors. It also does not fit into worker categories, which are differentiated depending on their mode of production. Included among these workers is everything from scientists, technology personnel, engineers, architects, innovators and entrepreneurs, musicians, artists, writers, and design and entertainment personnel. Also, the fact of requiring creation and being knowledge-based does not differentiate these products.

In fact, creativity and traditional knowledge are found in different places. In the case of painting, its value is associated with the artistic expression of the painter and goes beyond the price of the materials that are used. The products may be texts, drawings, videos, as well as the performing arts, music, symbols, and other suchlike things. Consequently, the activities of the creative sector can be considered as the economics of the intangible, of the symbolic, combining creativity and economics and having intellectual property as their value (Howkins, 2005).

What exists is the need for new forms of analysis for understanding activities that are circumscribed within those sectors that are considered part of the creative economy. A primordial distinction can be identified in these activities that reside much more in their process.

This process starts from the creation, production and distribution of products and services that use creativity, intellectual assets and knowledge as production resources. Economic activities are developed using creativity, techniques and technologies, which add value to the intellectual asset. This process can be characterized not only as a cultural asset, a marketable product or service, but it incorporates both tangible and intangible elements that are endowed with symbolic value. The notion of creativity can be defined as the process by which ideas are generated, connected and transformed into things, tangible or intangible products that have value" (Hui et al., 2005). Oliveira et al. (2013) even cite creative capital, having as its determinants four types of capital: social, cultural, human and structural.

Creation can be identified in the process itself and not just in the result. In this category of activities, it can be identified as flows in this process that entails moveable, volatile, and, sometimes, brilliant results. The interpretation of a character, for example, may be considered to be a volatile product. Some attributes of creation, such as talent and skills, are part of capital and knowledge, have a dynamic and are mobile. The use of creativity is considered an essential resource for generating value, thus configuring it as a category.

\section{FINAL CONSIDERATIONS}

The creative activities' scenario in the country is rich and, at the same time, marked by diversity. What seems to differentiate the creative experience from other activities can be seen particularly when it is found in individual projects. This can also be noticed with craftspeople in individual and family projects, or those in traditional communities.

The cases here analyzed show the experiences of workers who seek ways to develop products that can generate income for their survival. The study also identified that this is work in which creativity is emphasized as being part of the production process, and that involves talent and technology. It also identified that these women feel that as producers 
and creators they are contributing to society by way of the work they do, which has a value.

In this sense, two points can be identified in the experiences of the interviewees, who are in activities involving categories that are considered creative: first, the positive relationship that they establish with the work process; second, the positive relationship they manage to establish with the result or the product of their work.

It is worth distinguishing what the worker feels is the result of their work and the satisfaction they feel when they see the result of the work that possesses materiality. This is especially true when they target the end user and they are in an activity of their own choosing. In the cases interviewed, away from the production line, the activity allows the craftspeople to master the work process, since they project and develop their ideas, thereby achieving greater satisfaction with the result of what they produce. They feel that they produce something new, by their creation, especially when they chose the activity and they are self-employed. Even if these producers are subject to the same consumption patterns, which are established in the relationship with the user - and many of these consumers or users have similar behaviors - the possibility of creation seems to be present, since they decide on how the end product will be developed, and the consumer acquires it as it is. Those who are involved in creative activities, even when they are on the production line, also consider that they have a certain possibility of innovating, of creating. They do so, even considering that there are limitations to this creation, since they must meet a requested demand, but the activity they develop allows for some innovation.

The issue of the value that is attributed to these activities is still a problematic aspect. If the sectors in the major creative, cultural, media, advertising, software and gaming industries that develop products and establish their agendas, and their products, which are normally directed at large companies and a large audience, generate wealth and greater added value, the same does not occur with those who are in creative activities in general. The products of small individual producers, those who dedicate themselves to the performing arts and literature, craftsmen, and those who use traditional knowledge, are directed at other users and they are not always valued.

The time issue is related to value. The production of a show, for example, demands several periods of time, including preparing the project, project presentation, research and rehearsals, and not all of them are counted. Consequently, the work may not always be properly valued. Many people are not paid sufficiently to cover these times. In this sense, mastering time is always a challenge to be faced by these individual producers, or in collective projects. Individual producers who work on their own need to divide their time with other activities that take longer. For those who are in consultancy projects, and who need to meet other demands, the pressure on time is a little greater. For those who work in traditional activities, such as the lace-makers, the difficulties are very great. There is a distance between the time spent in making items in lace, along traditional lines, and the amount that is paid for each item. The same applies to those who work with handicrafts. They spend a lot of their working hours on creating and producing the item. There is also the time when the product is on display to be sold. For those who work in the theater and writing, there is the time spent preparing projects, in presenting them, in rehearsals, and the return they actually receive in terms of remuneration or income.

Being valued as a producer and creator also depends on the support received for overcoming these different times; support for performing arts groups, for example; support for dealing with the challenges they face, for accounting for the time spent in activities that are considered marginal, such as presenting projects and rehearsals; and support for enabling a greater closeness between producers and buyers for reducing the bill of the time between when a handmade item is ready to be sold and when it is actually sold. These producers, craftspeople, are dependent on public policies that help ensure that the value of their work is transformed into financial return.

\section{ACKNOWLEDGEMENTS}

We should like to thank all who gave us testimonials, producers who dedicated their precious time to talk about their activities, their production. A copy of the text was sent to everyone before being submitted to the journal. Ethical standards were followed, ensuring anonymity as well as respecting omissions and questions that could not be answered.

\section{REFERENCES}

Adorno, T.W.; Horkheimer, M. (1985), Dialética do esclarecimento, Editora Zahar, São Paulo.

Boyer, R. (1998), Après fordisme, Syros, Paris.

Brasil (2012), Plano da Secretaria de economia criativa, MEC, Brasília.

Castoriadis, C. (1982), A instituição imaginária da sociedade, Paz e Terra, Rio de Janeiro.

Castoriadis, C. (1987), As encruzilhadas do labirinto: os domínios do homem, Vol. 2, Paz e Terra, Rio de Janeiro.

Florida, R. (2002), The Rise of the Creative Class, Perseus, New York. 
Florida, R. (2006), The Flight of the Creative Class, Harper Collins, New York.

Gianini (2013), La "reflexion" cotidiana. Hacia uma arqueologia de la experiência, Universidad Diego Portales, Santiago.

Howkins, J. (2001), The creative economy: how people make money from ideas, Penguin, London.

Howkins, J. (2005), "The mayor's commission on the creative industries", in: Hartley, J. (Ed), Creative Industries, Blackwell, London.

Hui, D. et al. (2005), "A study on creativity index", Home Affairs Bureau - The Hong Kong Special Administrative Region Government.

Itani, A. (2014), "Work experience”, Psychology, Vol. 5.

Kon, A. (2016). "On the creative economy chain in Brazil: potential and challenges", Brazilian Journal of Political Economy, Vol. 16, No. 1.
Meyer, G. et al. (2016), "Entidades performáticas e desestabilização: o desenvolvimento local para além do mainstream", Interações, Vol. 17, No. 1, pp. 33-45.

Miguez, P. (2007), “Economia criativa: uma discussão preliminar", in: Nussbaumer, G.M. (org.), Teorias e políticas da cultura: visões multidisciplinares, EDUFBA, Salvador.

Nicolaci-da-Costa, A. M. (2011), "O talento jovem, a internet e o mercado de trabalho da "economia criativa", Psicologia \& Sociedade, Vol. 23, No. 3.

Oliveira, J.M. (2013), Panorama da economia criativa no Brasil (texto para discussão), IPEA, Brasilia.

United Nations Conference on Trade and Development - UNCTAD (2010), Creative economy Report, UNCTAD, New York.

Received: Sept 13, 2017

Approved: Jan 29, 2018

DOI: 10.14488/BJOPM.2018.v15.n1.a5

How to cite: Itani, A.; Rei, F. (2018), "Workers, producers and the creative experience”, Brazilian Journal of Operations \& Production Management, Vol. 15, No. 1, pp. 386-395, available from: https://bjopm.emnuvens.com.br/ bjopm/article/view/398 (access year month day). 